\title{
Estimating inventory stocks for greenhouse heating needs
}

\author{
S Kurpaska ${ }^{1}$, A Krakowiak-Bal ${ }^{1}, M_{\text {Gliniak }}{ }^{1}, K_{\text {Trzyniec }}{ }^{1}$ and K Nęcka ${ }^{1}$ \\ ${ }^{1}$ Faculty of Production and Power Engineering, the University of Agriculture in \\ Krakow, Balicka 116b, 30-149 Kraków, PL \\ E-mail: rtkurpas@cyf-kr.edu.pl
}

\begin{abstract}
Paper deals with the problem of supply logistic for greenhouse energy purposes. It is an attempt to estimate the proper supplies of coal, to reduce the costs of warehouse management in the analyzed horticultural enterprise. The analysis includes estimation of the object's heat demands of the, an optimal order quantity and calculation of costs of maintaining inventory. The research object is a greenhouse complex (10 ha) with tomatoes cultivation. We calculated that, the proposed inventory shaping method, to determine the order quantity of energy raw material for the needs of the greenhouse, would reduce inventory financing costs by $33.5 \%$.
\end{abstract}

\section{Introduction}

Greenhouse production, in the era of searching for healthy and safe food, is one of the important sectors of plant production which guarantees a year-round supply of vegetables. The means of production to ensure the functioning of the greenhouse facility include planting material, pesticides, electricity, water, labour inputs. Besides, a significant position in expenditure balance is heat carrier cost.

In Poland, as well as in other EU countries, alternative energy sources are being sought and there is a constant replacement of coal with other conventional fuels (heating oil, natural gas). However, according to available statistics, coal is still the primary fuel. Increased costs of heating in production facilities, legal regulations (plan "three 20 targets" assuming the reduction of harmful emissions from fossil fuels combustion) force to reduce heat consumption in horticultural facilities. One such solution is to increase the walls insulation of heated objects (greenhouses and plastic tunnels). In addition to glass, single or double foil (with pressed compressed air), polycarbonate can be used as a greenhouse cover. This material is characterized by a lower heat transfer value, however, a certain drawback concerning glass or foil is the lower transmission of visible light and reduction of this permeability over time.

The issue of reducing heat demand by horticulture facilities has been intensively studied in many scientific centres. The research concerned both the technical equipment of the object and the impact of the cover type (with varying insulation) on heat consumption. Also, the search for alternative heat carriers and minimizing fuel consumption is the subject of interest for numerous research centres. Ossebaard et al. [1] presented an analysis of the use of individual energy sources for heating (both renewable and traditional), taking into account economic and ecological effects. The purposefulness of replacing the traditional heat carrier (gas) by renewable energy was stated. Hawlader et al. [2] studied energy effects and payback period for the bivalent system (solar collectors, heat pump) from which heat was supplied to prepare heating water. Ozgener and Hepbasli [3] analyzed the energy and 
economic issues of the monovalent system (heat pump with ground heat exchangers) for greenhouse heating. Garcia et al. [4] considered the possibility of using various heat sources (traditional and renewable) for heating greenhouses located in different climate zones. They noticed that in the Mediterranean countries the best results will be obtained by using solar collectors, while in countries located in northern European regions it is best to support heating with a heat pump. They stated the need to store in energy accumulators, the surplus energy that arose as a result of passive heating of the greenhouse interior. Hamdan et al. [5] analyzed the use of renewable energy sources for greenhouse heating. The work efficiency of independent sources (heat pump, solar collectors) and in the bivalent (hybrid) system as a connection of the pump with solar collectors was studied. Gustavsson and Svenningsson [6] demonstrated the benefits of replacing traditional heat carriers with energy from the biomass conversion for both heating purposes and fuel for transport means. Groscurth et al. [7] presented problems with the use of energy from renewable sources for heating purposes. They drew attention to the rational separation of existing renewable energy sources to minimize the emission of harmful substances resulting from the combustion of traditional heat carriers. Kurpaska and Latała [8] presented the results of research related to the energy and ecological effects of using a heat pump for foil tunnel heating. The analysis concerned the system in which the heating pump operated in a hybrid system, i.e. the energy stored in the liquid tank was used as the lower heat source. Chau et al. [9] conducted a technical and economic analysis for a typical boiler powered with pellets and waste wood for greenhouse heating. The NPV indicator used in the economic analysis showed that installing a biomass boiler, with an assumed $40 \%$ coverage of heat demand, is more profitable than a natural gas boiler. Ahmed et al. [10] analyzed heat demand for year-round production and an assessment of the economic feasibility for the production of greenhouse vegetables (tomato, cucumber and pepper) in a conceptually designed greenhouse (0.6 ha) located in northern Canada. Canakci and Akinci [11] analyzed the total energy consumption in vegetable production in Turkey, concluding that the highest consumption value relates to the production of tomatoes and cucumbers, while the lowest to the production of peppers and eggplants. Mohammadi and Omid [12] determined the components of the production means for the cucumbers cultivation. It was found that the largest component (nearly $42 \%$ ) is heat energy.

To sum up, it can be stated that the issues related to the reduction of production costs are an interesting research issue undertaken in various scientific centres. An important problem is to ensure the continuity of fuel supply and minimize storage costs. The volume of coal stocks in the enterprise is an essential element of its financial position. Excessive inventories engage financial resources, it leads often to frozen assets (working capital) and reduction of the current financial liquidity of the enterprise. On the other hand, the shortage of inventories may upset the production continuity, thus causing additional costs associated with replenishing materials to the desired level.

Excessive storage entails high storage costs but eliminates the problem of lack of raw materials, materials or intermediate products, as well as the problem of place orders. On the other hand, insufficient stock increases the risk of lack of inventories and increases the frequency of orders. These two opposite approaches generate costs associated with inventory management. The ideal solution would be a just in time delivery system for raw materials, materials and semi-finished products. Economic practice indicates, however, that on-time deliveries (without stocks accumulation) represent only a small percentage of all deliveries.

Therefore, it is necessary to determine the optimal size and dates of delivery to replenish the stock in terms of the adopted criterion. Also, the growing importance of the environmental costs of storing and handling coal should be taken into account. Akshaya and Muller [13] indicated that a one ton increase in coal stockpiles results in local air pollution costs of $\$ 197$.

It seems that the best decision-making criterion is to minimize the total costs associated with inventory management, taking into account various possible aspects of this decision. The main purpose of this work is the analysis of inventory storage in horticultural objects. 


\section{Material and Method}

The research object is a production greenhouse complex (10 ha) with tomatoes cultivation throughout the year. The scheme of the analyzed object illustrates Fig. 1.

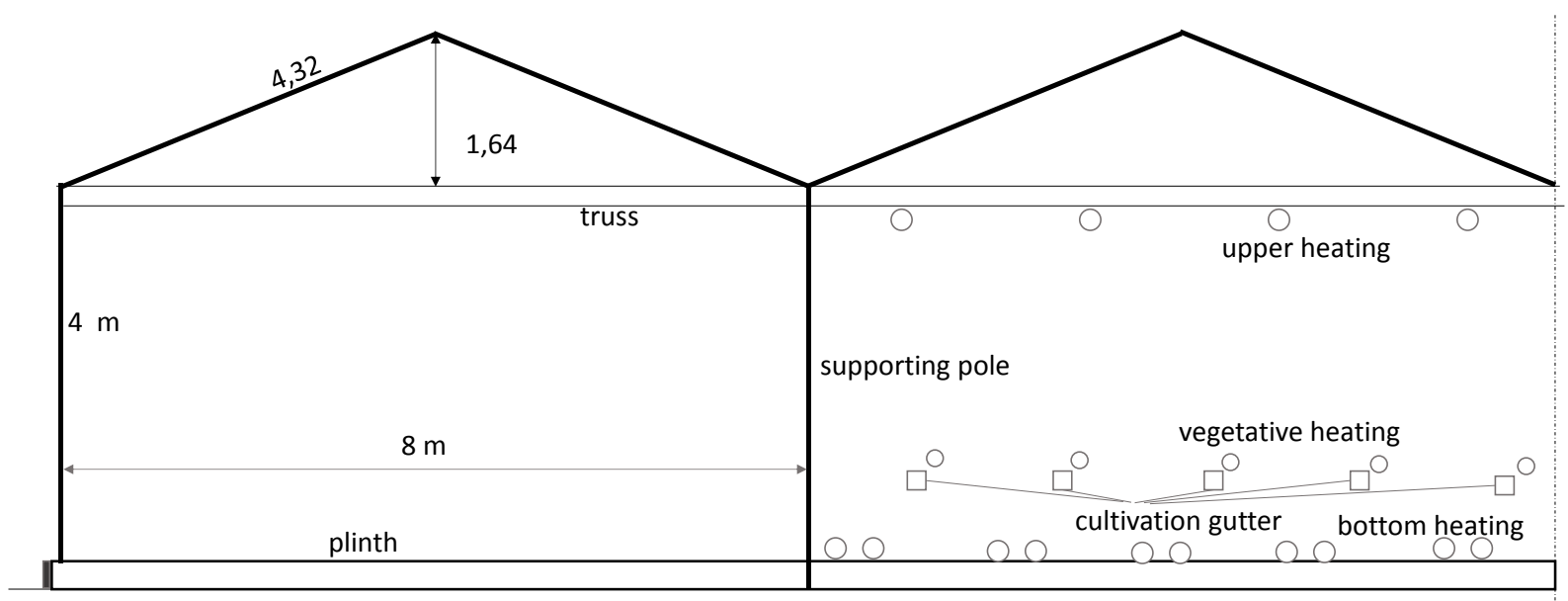

Figure 1. The scheme of the analyzed object.

The facility consists of 10 independent greenhouse blocks with dimensions, respectively length $\mathrm{x}$ width: $104 \times 96 \mathrm{~m}$. Heat screens are installed in the facility. To ensure continuous heat supply, the greenhouse complex has a coal-fired boiler room. Table 1 summarizes the required data to calculate heat demand.

Table 1. Characteristic parameters of the analyzed greenhouse.

\begin{tabular}{lccc}
\hline Specification & \multicolumn{3}{c}{4 meters high greenhouse } \\
\hline & area, $\left[\mathrm{m}^{2}\right]$ & cover indicator*, [-] & volume indicator, $\xi,[-]$ \\
glass & 12540 & & 5.12 \\
concrete & 120 & 1.254 & \\
polystyrene & 120 & & \\
\end{tabular}

Cover indicator *: relation of the glass surface to the greenhouse cultivation area

To estimate the daily demand heat, a standard differential heat balance method was used, which for the considered time $\mathrm{d} \tau$ for individual mechanisms takes the form:

a) heat transfer through the cover:

$$
Q_{h}=U \cdot F \cdot\left(t_{\text {out }}-t_{\text {ins }}\right) d \tau
$$

b) infiltration

$$
Q_{\text {inf }}=0,278 \cdot i \cdot \xi \cdot c_{w} \cdot \rho \cdot F_{\text {ob }} \cdot\left(t_{\text {out }}-t_{\text {ins }}\right) d \tau
$$

c) soil conduction 


$$
Q_{g r}=\left\{U_{1} \cdot F_{o b 1} \cdot\left(t_{i n s}-t_{g r 1}\right)+U_{1} \cdot F_{o b 2} \cdot\left(t_{i n s}-t_{g r 2}\right)\right\} d \tau
$$

where:

$U$ - heat transfer coefficient (calculated separately for the cover and base) $\mathrm{W} / \mathrm{m}^{2} \mathrm{~K} ; F$ - heat exchange surface (separately for base and covers), $\mathrm{m}^{2} ; t_{\text {out }}$ - average monthly ambient temperature, ${ }^{\circ} \mathrm{C}$; $t_{\text {ins }}$ - the temperature inside the object, ${ }^{\circ} \mathrm{C} ; \xi$ - air exchange rate, $1 / \mathrm{hr} ; \rho$-air density, $\mathrm{kg} / \mathrm{m}^{3}$; $c_{w}$-specific heat of moist air, $\mathrm{kJ} / \mathrm{kg} \mathrm{K} ; F_{o b^{-}}$greenhouse cultivation area, $\mathrm{m}^{2} ; U_{l}, U_{2}$ - heat transfer coefficient to the ground in zone $1\left(U_{1}\right)$ and in zone $2\left(U_{2}\right), \mathrm{W} / \mathrm{m}^{2} \mathrm{~K} ; F_{o b l} ; F_{o b 2}$ area of zones, respectively zone $1\left(F_{o b l}\right)$ and zone $2\left(F_{o b 2}\right), \mathrm{m}^{2} ; t_{g r l}, t_{g r 2}$ - temperature of zones $(1 \mathrm{i} 2),{ }^{\circ} \mathrm{C}$.

Hence, the total heat demand is:

$$
Q_{t o t}=Q_{h}+Q_{i n f}+Q_{g r}
$$

Based on the calculated monthly heat demand values, the fuel demand was calculated using the formula:

$$
m_{\text {coal }}=\frac{Q_{t o t}}{\eta \cdot W_{u}}
$$

With the calculated value of fuel demand, the optimal delivery batch was determined. The method of determining the optimal order size allows calculating the exact order quantity at which the total inventory costs are minimal [14]. The $E O Q$ formula can be modified to determine different production levels or order intervals or high variable costs. This inventory model is also applicable in conditions of nonlinear stock dependent demand and nonlinear holding cost [15]. EOQ is also an important cash flow tool. The formula can help a company control the amount of cash tied up in the inventory balance.

The Optimal Economic Order Quantity $(E O Q)$ is expressed by the formula:

where:

$$
E O Q=\sqrt{\frac{2 S O}{C}}
$$

$S$ - material consumption of a specific type or group of assortment expressed in natural units in a given period for a given production volume, $O$ - unit cost of ordered supply materials, $C$ - fixed costs related to storage of ordered materials in a given period.

Also, the planning of supply logistics should include the costs of maintaining inventory, which cover:

- storage costs,

- costs of capital involved in stocks,

- inventory obsolescence costs.

The entire storage costs are generally treated as fixed costs and determined according to the relationship [16]:

$$
C=M_{Z} s_{m}
$$

where:

$C$ - total storage costs, $M_{z}$ - average inventory, $s_{m}$ - empirically determined storage cost index in $\%$ of inventory value.

Storage costs, including mainly storage costs, are relatively constant. The annual unit cost of maintaining inventories was set at $5 \%$ of the inventories value.

The cost of capital involvement was determined according to the relation: 
where:

$$
K_{f}=\overline{M_{z}} \overline{s_{o}}
$$

$K_{f}$ - the cost of capital employed, $\overline{M_{z}}$ - average inventory volume, $\overline{s_{o}}$ - average interest rate (determined as $1.5 \%$ )

The costs of capital involved inventories express alternative benefits that these capitals could bring if they were not allocated in stocks.

The analysis includes two different variants of stock management, Variant 1 is used in the enterprise, and variant 2 is an attempt to model this process.

\section{Results and discussion}

The following values were adopted for detailed analysis: heat exchange surface, shield indicator (based on data in Table 1), index $\xi$ was adopted as $\xi=0.5$. The calculations include the existing insulation of the greenhouse base. The analysis took into account the average monthly air and ground temperature values indicated in Table 2 .

Table 2. The average monthly air temperature.

Specification Month

\begin{tabular}{lcccccccccccc}
\hline & I & II & III & IV & V & VI & VII & VIII & IX & X & X & XII \\
Air temperature, ${ }^{\circ} \mathrm{C}$ & $-3,3$ & $-1,6$ & 2,5 & 7,9 & 13,2 & 16,2 & 17,5 & 17 & 13,1 & 8,4 & 3,3 & $-0,9$ \\
Ground temperature, ${ }^{\circ} \mathrm{C}$ & $-3,3$ & $-1,1$ & 3,1 & 9,1 & 16,1 & 19,9 & 21,5 & 19,9 & 16,1 & 9,1 & 2,8 & $-2,0$
\end{tabular}

Besides, actual temperature settings inside the object were included: weather period with existing solar radiation at $20^{\circ} \mathrm{C}$; while at night $12^{\circ} \mathrm{C}$. Cultivation cycle was established from $15^{\text {th }}$ of December to $15^{\text {th }}$ of November, during the liquidation of the cultivation and preparation the greenhouse for the new season as: at night $4^{\circ} \mathrm{C}$, and during the day $10^{\circ} \mathrm{C}$.

Heat transfer coefficients $(U)$ were calculated from standard data, while the heat transfer coefficient was adopted following PN-EN 12831 standard: values of $U_{1}=1.94$ and $U_{2}=0.69 \mathrm{~W} / \mathrm{m}^{2} \mathrm{~K}$. The heat exchange surface was assumed as: $F_{o b 1}=400$ and $F_{o b 2}=9996 \mathrm{~m}^{2}$. The boiler efficiency was assumed at the level of $\eta=0.8$, and the calorific value of fuel $W_{u}=22 \mathrm{MJ} / \mathrm{kg}$.

Figure 2 shows the calculated monthly demand for the analyzed fuel (coal).

In the next stage of the analysis, the optimal order size was determined at the level of $E O Q=62.80$ tonnes, taking rounded value 70 tonnes. Based on total raw requirements and $E O Q$, the calculated optimal number of deliveries per year is seven.

It should be remembered that decisions on purchasing energy raw materials are made based on the prices of a given raw material during the year. The most favourable purchase prices for the raw material on the market are outside the heating season, which should be included in the planning of material needs and the number of stocks held. This aspect and modification were included in the proposed solution.

The costs of transporting the raw material are also significant, which in the analyzed case constitute approx. $10 \%$ of the purchase price. 


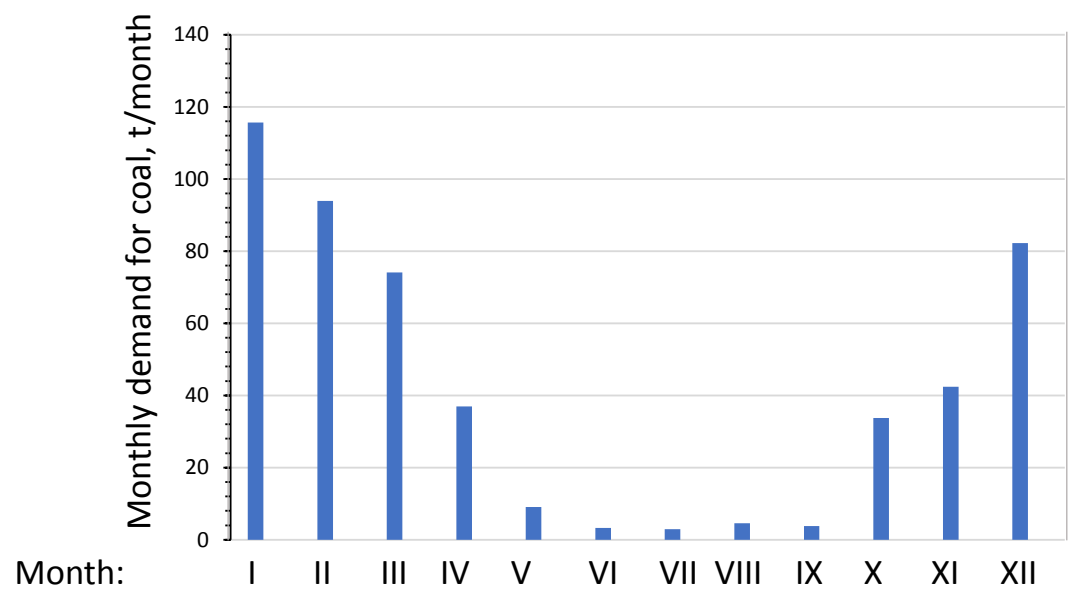

Figure 2. Monthly demand for coal for a 1 ha greenhouse.

Currently, in the analyzed facility (variant I), the raw material was ordered once, taking into account year-round needs. However, this is associated with the need to incur costs related to i.a: storage of a significant amount of raw material and the involvement of capital in its financing.

The proposed variant II takes into account the determined economic volume of the order implemented seven times a year outside the heating season in the period from April to October (it was assumed that the supply cycle should not be equal, due to the mentioned differences in the price of the raw material during the year).

Table 3 presents the determined values for the compared variants.

Table 3. Inventory management in compared variants for 1 ha greenhouse.

\begin{tabular}{|c|c|c|c|c|}
\hline Specification & & Variant 1 & Variant II & Difference \\
\hline $\begin{array}{l}\text { average inventory } \\
\text { volume }\end{array}$ & tones/year & 351.4 & 233.8 & 117.6 \\
\hline inventory value & euro & 26241.0 & 17458.5 & 8782.461 \\
\hline $\begin{array}{l}\text { cost of capital } \\
\text { involvement } K_{f}\end{array}$ & euro & 393.6 & 261.9 & 131.7 \\
\hline storage cost $C$ & euro & 1312.0 & 872.9 & 439.1 \\
\hline $\begin{array}{l}\text { annual fuel demand } \\
m_{\text {coal }}\end{array}$ & tones/year & & 502.7 & \\
\hline
\end{tabular}

Comparing both variants, it can be seen that both the quantity and value of the raw material inventory is significantly lower. The average annual stock is lower by 117 tonnes, which in value corresponds to an amount of 8,800 euro. Lower inventories naturally reduce their financing costs, which in this case were reduced by 131 euro. It should be emphasized that all values refer to 1 ha of greenhouses.

\section{Conclusions}

Logistic decision optimization methods are widely used and can be adopted in any business activity. 
In the paper, on the example of numerical values characterizing the complex of production greenhouses, real savings possible to be generated by the application of economical methods of fuel stocks controlling were indicated.

Based on presented results it can be concluded:

- the application of the inventory shaping method, to determine the order quantity of energy raw material for the needs of the greenhouse, would reduce inventory financing costs by $33.5 \%$,

- the volume of inventories kept in the enterprise decreased by over a third, which directly affects its financial condition (financial liquidity).

One of the most important task for companies is to improve their efficiency, understood as cost optimization. Properly selected supply processes can generally reduce the amount of accumulated inventory, which can significantly affect costs while guaranteeing the continuity of production.

To stay on the market and gain a competitive advantage, an enterprise must have an efficient logistics system. Without a well-planned, organized, managed and controlled logistics system, the company has no chance of surviving in ever-changing market conditions and amid growing competition.

Besides, the costs of maintaining a high level of inventories increase the costs of business operations, and thus the costs of manufactured products, which are ultimately borne by consumers (recipients). Not without significance is the fact that each additional stored ton of coal also generates additional environmental costs. One of the solutions is planning supplies with the use of an optimal order size, which allows reducing the costs of warehouse management in the analyzed horticultural enterprise.

\section{Acknowledgements}

This research was financed by the Ministry of Science and Higher Education of the Republic of Poland to statutory activities DS-3600/WIPiE, Faculty of Production and Power Engineering, the University of Agriculture in Krakow.

\section{References}

[1] Ossebaard M E, Van Wijk A J M and Van Wees M T 1997 Heat supply in The Netherlands: A system analysis of costs, exergy efficiency, $\mathrm{CO}_{2}$, and $\mathrm{NO}_{\mathrm{x}}$ emissions Energy 22 pp 1087-1098

[2] Hawlader M N A, Chou S K and Ullah M Z 2001 The performance of a solar assisted heat pump water heating system Appl. Therm. Eng 21 pp 1049-1065

[3] Ozgener O and Hepbasli A 2005 Exergoeconomic analysis of a solar assisted ground-source heat pump greenhouse heating system Appl. Therm. Eng 25 pp 1459-1471

[4] Garcia J L, De la Plaza S, Navas L M, Benavente R M and Luna L 1998 Evaluation of the Feasibility of Alternative Energy Sources for Greenhouse Heating J. Agric. Eng. Res.69 pp 107-114

[5] Hamdan M A, Al-Sayeh A I and Jubran B A 1992 Solar hybrid heating systems for greenhouses Appl. Energy 41 pp 251- 264

[6] Gustavsson L and Svenningsson P 1996 Substituting fossil fuels with biomass Energ Convers Manage 37 pp 1211-1216

[7] Groscurth H M, Bruckner T and Kummel R 1993 Energy cost and carbon dioxide optimization of disaggregated regional energy-supply systems Energy 18 pp 1187-1205

[8] Kurpaska S and Latała H 2013Wytyczne konstrukcyjne dla systemu wykorzystującego pompę ciepła na potrzeby ogrzewania obiektu ogrodniczego Inżynieria Rolnicza 3 pp 169-178

[9] Chau J, Sowlati T, Sokhansanj S, Preto F, Melin S and Bi X 2009 Techno-economic analysis of wood biomass boilers for the greenhouse industry Appl. Energy 86 pp 364-71

[10] Ahamed M S, Gua H, Taylor L and Tanino K 2019 Heating demand and economic feasibility analysis for year-round vegetable production in Canadian Prairies greenhouses Information Processing in Agriculture 6 pp 81- 90

[11] Canakci M and Akinci I 2006 Energy use pattern analyses of greenhouse vegetable production 
Energy 31 pp 1243-1256

[12] Mohammadi A and Omid M 2010 Economical analysis and relation between energy inputs and yield of greenhouse cucumber production in Iran Appl. Energy 87 pp 191-196

[13] Jha A and Muller N Z 2018 The local air pollution cost of coal storage and handling: Evidence from U.S. power plants J. Environ. Econ. Manage 92 pp 360-396

[14] Lucey T 2002 Quantitative techniques Cengage Learning EMEA

[15] Cárdenas-Barrón L E, Shaikh A A, Tiwari S and Treviño-Garza G 2018 An EOQ inventory model with nonlinear stock dependent holding cost, nonlinear stock dependent demand and trade credit Comput. Ind. Eng. 105557

[16] Skowronek Cz and Sarjusz - Wolski Z 2012 Logistyka w przedsiębiorstwie Polskie Wydawnictwo Ekonomiczne 